Article

\title{
Effect of Ionic Liquids on the Isobaric Vapor-Liquid Equilibrium Behavior of Acetone-Chloroform
}

\author{
Qinglin Gao ${ }^{1}$, Zongchang Zhao ${ }^{1, *}$, Peng Jia ${ }^{1}$ and Xiaodong Zhang ${ }^{2}$ \\ 1 School of Chemical Engineering, Dalian University of Technology, Dalian 116024, China; \\ gaoqinglin@mail.dlut.edu.cn (Q.G.); jiapeng_1988@163.com (P.J.) \\ 2 Chemical Machinery School, Dalian University of Technology, Dalian 116024, China; xdzhang@dlut.edu.cn \\ * Correspondence: zczhao55@163.com; Tel.: +86-0411-8498-6171
}

Received: 30 July 2018; Accepted: 22 August 2018; Published: 1 September 2018

\begin{abstract}
Isobaric vapor-liquid equilibrium (VLE) data of the ternary system acetone + chloroform + 1,3-dimethylimidazolium dimethylphosphate ([MMIM][DMP]) or 1-ethyl-3-methylimidazolium diethylphosphate ([EMIM][DEP]) were obtained at $101.3 \mathrm{kPa}$. Results indicated that the addition of [MMIM][DMP] or [EMIM][DEP] could eliminate the azeotropic point of the binary system of acetone + chloroform when the mole fraction of ionic liquids (ILs) was above 0.15. Besides, the experimental data could be well correlated by the nonrandom two-liquid (NRTL) model. The structures as well as interactions between molecular solvents (acetone, chloroform) and the ion pairs ([MMIM][DMP], [EMIM][DEP]) were studied by quantum chemical calculations. The result indicated that the interaction energies $(\Delta E)$ follow the order of $\Delta E$ (acetone $+[$ EMIM] [DEP]) $>$ $\Delta E($ acetone $+[$ MMIM $][\mathrm{DMP}])>\Delta E($ chloroform $+[$ EMIM $][\mathrm{DEP}]) \approx \Delta E($ chloroform $+[$ MMIM] [DMP] $)$, and chloroform had stronger affinity to ionic liquids than acetone.
\end{abstract}

Keywords: ionic liquid; vapor-liquid equilibrium; NRTL model; acetone; chloroform; quantum chemical calculation

\section{Introduction}

Acetone and chloroform are extremely important solvents in the chemical industry, especially in the medical field. It is difficult for conventional distillation to separate them because acetone and chloroform attract each other, forming hydrogen bonds and producing a maximum-boiling azeotrope [1]. In various techniques of separating the azeotropic system, extractive distillation is commonly used in industry and a suitable entrainer is crucial to the process of separation [2,3]. Luyben [4] studied several solvents to separate the acetone-chloroform system and found that dimethyl sulfoxide was an appropriate extraction solvent.

Compared with traditional entrainers or inorganic salts, ILs have some characteristics, e.g., non-volatility, tunable solubility for many organic compounds, good stability, and so on [5]. In this study, [MMIM][DMP] and [EMIM][DEP] were applied to separate acetone + chloroform binary azeotropic system as entrainers. The VLE data for the ternary system containing [MMIM][DMP] or [EMIM][DEP] were measured at $101.3 \mathrm{kPa}$. Meanwhile, the NRTL model was utilized to correlate the VLE data.

In order to study the mechanism of ILs as entrainer, it is important to clarify the interactions between ILs and solvent molecules. Quantum chemical calculation is a means to study the interactions between ILs and solvent molecules [6-8]. In this work, after geometry optimization and frequency analysis calculations, the intermolecular energies were calculated with DFT, basis set superposition error (BSSE) correction, and zero-point energy (ZPE). 


\section{Materials and Methods}

\subsection{Chemicals}

Acetone and chloroform were purchased from Beijing Chemical Reagents Company (Beijing, China). The mass fraction of acetone and chloroform were higher than $99.5 \%$ checked by gas chromatography. The ILs ([MMIM][DMP] and [EMIM][DEP]) were made in our laboratory and the mass fraction higher than $98.0 \%$ checked by $1 \mathrm{H}$ NMR. In order to remove the volatile impurities and water, the ILs were dried in a vacuum rotary evaporation $(2 \mathrm{kPa}, 393 \mathrm{~K})$ for $48 \mathrm{~h}$. The mass fraction of water in ILs was below $0.05 \%$ examined by Karl Fischer titration. In addition, the used ILs were recycled in the same way after experiments.

\subsection{Apparatus and Procedure}

The VLE data were measured by a modified Othmer still at $101.3 \mathrm{kPa}$. The detailed description of this apparatus can be found in reference paper [9]. The VLE experiments were analyzed by a gas chromatograph (GC7900, Techcomp, Shanghai, China) equipped with a GDX-102 column $(2 \mathrm{~m} \times 3 \mathrm{~mm})$ under pressure $(0.1 \mathrm{MPa})$ of the headspace sampler and a TCD detector for which the carrier gas is $\mathrm{H}_{2}$. The oven temperature, the injector temperature, and the detector temperature were $433.15 \mathrm{~K}, 453.15 \mathrm{~K}$, and $463.15 \mathrm{~K}$, respectively.

In order to quantify the amounts of acetone and chloroform, a calibration curve was obtained from a series of gravimetrically prepared standard solutions by an electronic balance with an uncertainty of $0.1 \mathrm{mg}$. The content of IL in the liquid phase was calculated by measuring the mass difference of the samples with and without IL. The VLE data were measured by GC only if the VLE temperature stayed constant for at least $30 \mathrm{~min}$. Each sample was analyzed 3 times to eliminate the error. The maximum uncertainty of the mole fraction of acetone and chloroform is \pm 0.002 . In the laboratory, the VLE pressure was measured by a mercury manometer with an uncertainty of $0.01 \mathrm{kPa}$. The VLE temperature was measured by a precisely calibrated thermometer with an uncertainty of $0.1 \mathrm{~K}$. According to the method provided in the literature [10], the temperature of the boiling point under actual pressure was corrected to the temperature at standard pressure $(101.3 \mathrm{kPa})$.

\section{Results and Discussion}

\subsection{VLE Data}

In order to check the reliability of the apparatus, the isobaric VLE data of acetone and chloroform were obtained at $101.3 \mathrm{kPa}$. The binary VLE data compared with literature [11] are given in Table A1 in Appendix B and Figure 1. It can be seen that the experimental data are consistent with those values in literature. Therefore, the apparatus is reliable for measuring the VLE data of the ILs-containing systems.

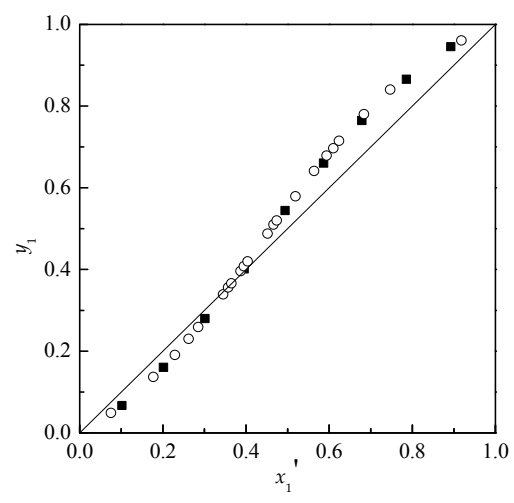

Figure 1. Isobaric vapor-liquid equilibrium (VLE) diagram for the system of acetone (1) + chloroform (2) at $101.3 \mathrm{kPa}$. Experimental value, $\bigcirc$ Literature value. 
The VLE data for the ternary systems of acetone (1) + chloroform (2) + [MMIM][DMP] (3) and acetone (1) + chloroform (2) + [EMIM] [DEP] (3) were obtained at $101.3 \mathrm{kPa}$, and the IL mole fraction was kept constant in each of the three series at $x_{3} \approx 0.100,0.150,0.200$. Results are reported in Tables A2 and A3 in Appendix B, where $x_{3}$ is the mole fraction of IL in the liquid phase, $x_{1}{ }^{\prime}$ is the mole fraction of acetone in the liquid phase without ILs, $y_{1}$ is the mole fraction of acetone in the vapor phase, $y_{1 \text { cal }}$ is corrected by NRTL, and Tis the equilibrium temperature. The activity coefficients $\gamma_{\mathrm{i}}$ and the relative volatility of acetone to chloroform $\alpha_{12}$ are calculated as follows:

$$
\begin{gathered}
\gamma_{i}=\frac{P y_{i}}{x_{i} P_{i}^{S}} \\
\alpha_{12}=\frac{\gamma_{1} P_{1}^{s}}{\gamma_{2} P_{2}^{s}}
\end{gathered}
$$

In Equations (1) and (2), $\gamma_{1}$ and $\gamma_{2}$ are the activity coefficient of acetone and chloroform respectively. $x_{i}$ and $y_{i}$ represent the mole fraction of component $i$ in the liquid phase and vapor phase, respectively. $P$ is the system pressure $(101.3 \mathrm{kPa}) . P_{i}{ }^{S}$ is the saturated vapor pressure of pure component $i$. In addition, $P_{i}{ }^{S}$ are calculated by Antoine equation and the parameters of Antoine equation can be obtained from literature [12].

\subsection{Modeling Results}

In 1968, Renon and Prausnitz [13] proposed the NRTL model, which was suggested by most authors to correlate the data of ternary VLE containing IL [14-16]. Thus, the experimental VLE data for acetone + chloroform and acetone + chloroform + ILs systems were also correlated by the NRTL model. The binary interaction parameters in the NRTL model were regressed by minimizing the function $O F$. The correlated results are listed in Table 1. The ARD (see Equation (4)) is the average relative deviation of the experimental and predicted mole fraction of acetone in the vapor phase.

$$
\begin{gathered}
\text { OF }=\sum_{1}^{n}\left(\left(1-\frac{\gamma_{1}^{\text {cal }}}{\gamma_{1}^{\text {exp }}}\right)+\left(1-\frac{\gamma_{2}^{\text {cal }}}{\gamma_{2}^{\text {exp }}}\right)\right) \\
A R D=\frac{1}{n} \sum_{n}\left|1-\frac{y_{1}^{\text {cal }}}{y_{1}^{\text {exp }}}\right|
\end{gathered}
$$

where $n$ is the number of experimental data points.

Table 1. Calculated Values of Binary Parameters $\Delta \mathrm{g}_{\mathrm{ij}}$ and $\Delta \mathrm{g}_{\mathrm{ji}}$ in the Nonrandom Two-Liquid (NRTL) Model.

\begin{tabular}{ccccc}
\hline $\mathbf{i}$ Component & $\mathbf{j}$ Component & $\boldsymbol{\alpha}_{\mathrm{ij}}$ & $\Delta \mathbf{g}_{\mathbf{i j}} / \mathbf{J} \cdot \mathbf{m o l}^{-\mathbf{1}}$ & $\Delta \mathbf{g}_{\mathrm{ji}} / \mathbf{J} \cdot \mathbf{m o l}^{-\mathbf{1}}$ \\
\hline acetone & chloroform & 0.399 & -198.209 & -11.766 \\
acetone & [MMIM][DMP] & 0.217 & 1006.802 & 2707.172 \\
chloroform & [MMIM][DMP] & 0.780 & 117.775 & 10.602 \\
acetone & [EMIM][DEP] & 0.023 & 1547.298 & -725.432 \\
chloroform & [EMIM][DEP] & 0.200 & -298.873 & -407.809 \\
\hline
\end{tabular}

According to the regressed parameters of NRTL model, the mole fraction of acetone in the vapor-phase was calculated. After the VLE data were measured and calculated, the $y-x^{\prime}$ diagrams for the ternary systems acetone + chloroform $+[$ MMIM] [DMP] and acetone + chloroform + [EMIM][DEP] are plotted in Figures 2 and 3. Meanwhile, the relative volatilities of acetone to chloroform are plotted in Figure 4. 


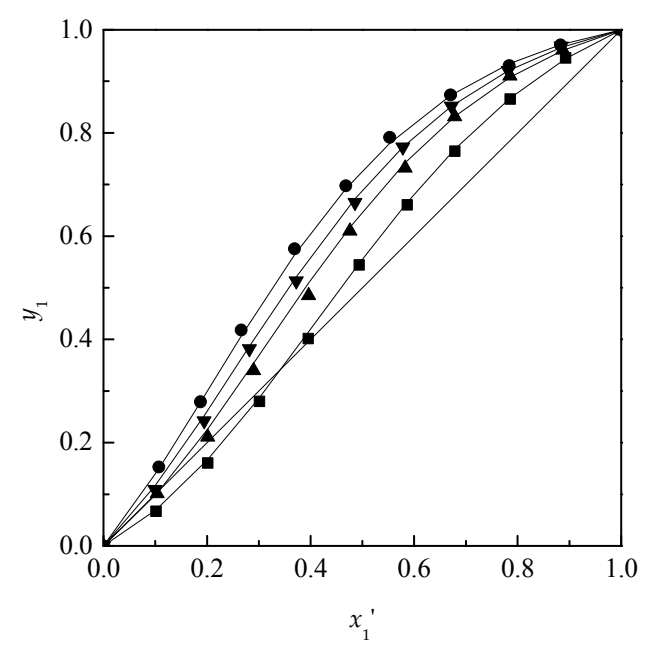

Figure 2. Isobaric VLE diagram for the system of acetone (1) + chloroform (2) + [MMIM][DMP] (3) at $101.3 \mathrm{kPa}: \mathbf{\square}, x_{3}=0 ; \boldsymbol{\Lambda}, x_{3}=0.10 ; \mathbf{\nabla}, x_{3}=0.15 ; \bullet, x_{3}=0.20$; solid line, calculated using NRTL model.

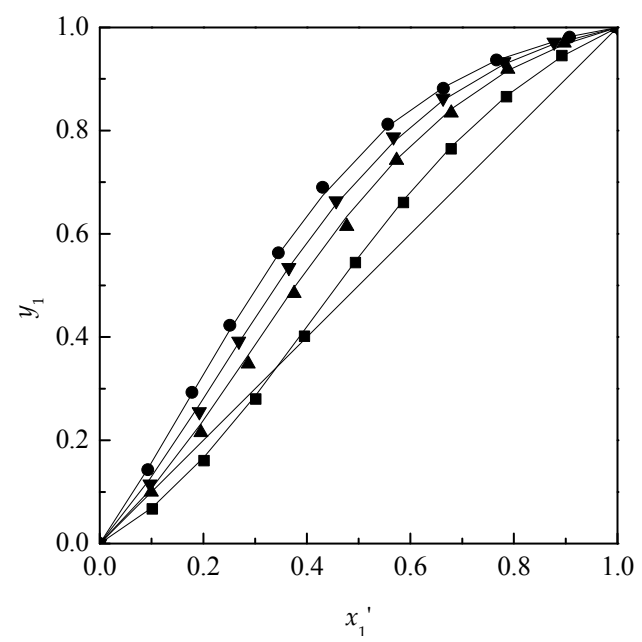

Figure 3. Isobaric VLE diagram for the system of acetone (1) + chloroform (2) + [EMIM][DEP] (3) at $101.3 \mathrm{kPa}: \mathbf{\square}, x_{3}=0 ; \mathbf{\Lambda}, x_{3}=0.10 ; \mathbf{\nabla}, x_{3}=0.15 ; \bullet, x_{3}=0.20$; solid line, calculated using NRTL model.

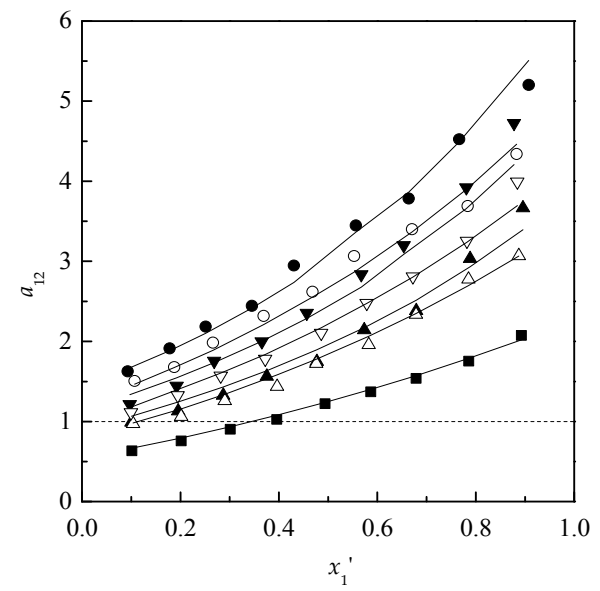

Figure 4. Relative volatility of acetone (1) + chloroform (2) containing [MIM][DMP] or [EMIM][DEP] (3)

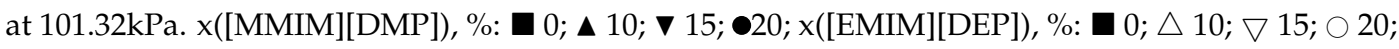
Solid line, calculated using NRTL model. 
As shown in Figures 2-4, with the increase of the ILs content, [MMIM][DMP] and [EMIM][DEP] produced more obvious salting-out effects for acetone and the salting-out effect followed the order: $20 \%>15 \%>10 \%$. Meanwhile, [EMIM][DEP] shows better separation efficiency than [MMIM][DMP] for the acetone-chloroform azeotrope by comparing the volatilities of acetone and chloroform. Because the value of $P_{1}{ }^{S} / P_{2}{ }^{S}$ has little change from 1.198 to 1.208 in the experiments, the increase of relative volatility could be attributed to the acute change of $\gamma_{1}$ and $\gamma_{2}$ with the addition of ILs. The activity coefficients of acetone and chloroform based on different mole fraction of ILs are shown in Figures 5 and 6.

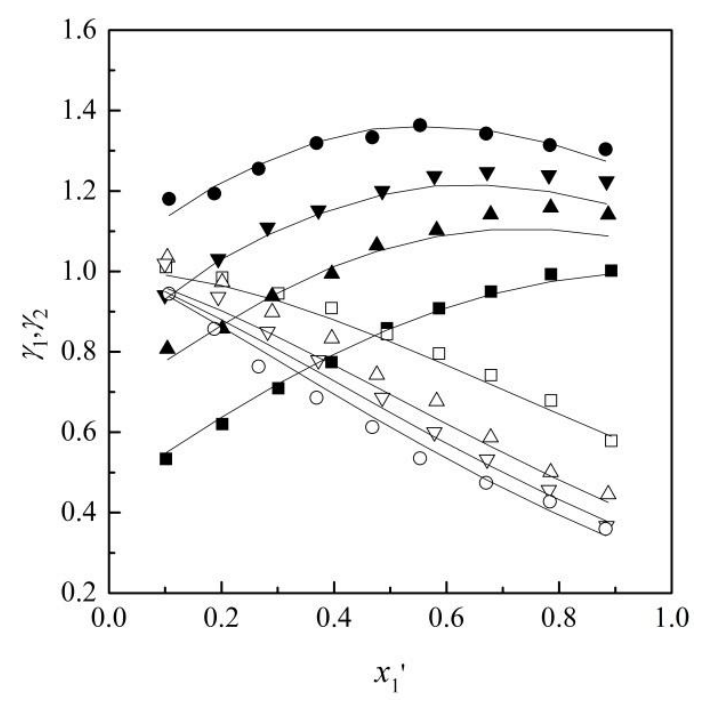

Figure 5. $\gamma_{1}\left(\gamma_{2}\right)-x_{1}{ }^{\prime}$ diagram for ethyl acetone (1) + chloroform (2) + [MMIM][DMP] (3) at 101.32 kPa: $\gamma_{1}-x_{1}{ }^{\prime}, \square \gamma_{2}-x_{1}{ }^{\prime}, x_{3}=0 ; \boldsymbol{\Delta} \gamma_{1}-x_{1}, \triangle \gamma_{2}-x_{1}{ }^{\prime}, x_{3}=0.10 ; \nabla \gamma_{1}-x_{1}{ }^{\prime}, \nabla \gamma_{2}-x_{1}{ }^{\prime}, x_{3}=0.15 ; \bullet \gamma_{1}-x_{1}{ }^{\prime}, \bigcirc \gamma_{2}-x_{1}{ }^{\prime}$, $x_{3}=0.20$; Solid line, calculated using NRTL model.

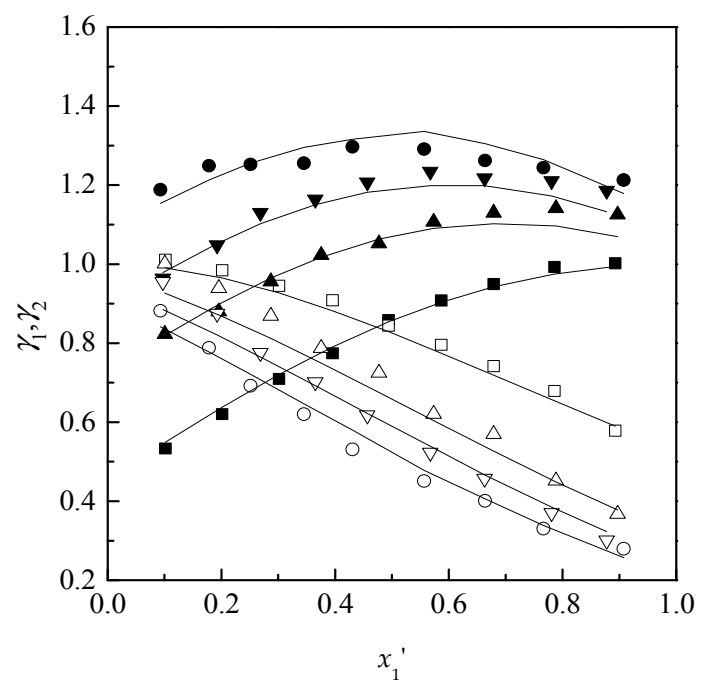

Figure 6. $\gamma_{1}\left(\gamma_{2}\right)-x_{1}{ }^{\prime}$ diagram for ethyl acetone (1) + chloroform (2) + [EMIM][DEP]( 3) at $101.32 \mathrm{kPa}$ $\gamma_{1}-x_{1}{ }^{\prime}, \square \gamma_{2}-x_{1}{ }^{\prime}, x_{3}=0 ; \boldsymbol{\Delta} \gamma_{1}-x_{1}, \triangle \gamma_{2}-x_{1}{ }^{\prime}, x_{3}=0.10 ; \nabla \gamma_{1}-x_{1}{ }^{\prime}, \nabla \gamma_{2}-x_{1}{ }^{\prime}, x_{3}=0.15 ; \bullet \gamma_{1}-x_{1}{ }^{\prime}, \bigcirc \gamma_{2}-x_{1}{ }^{\prime}$, $x_{3}=0.20$; Solid line, calculated using NRTL model.

It is observed that with the increased content of ILs, the values of $\gamma_{1}$ increased and $\gamma_{2}$ decreased over the whole range of studies. Therefore, the effect contributes to the increase in the relative volatilities and removes the azeotropic point. 


\section{Quantum Chemical Calculations}

In order to find the global minimum energy geometry, several initial configurations were optimized and their final energies were compared using the method of quantum chemical calculations. In this work, all initial configurations were optimized at the B3LYP /6-311++ $G^{* *}$ level with the Gaussian 09 software package [17].

After the geometry optimization, the intermolecular energies were calculated with DFT, basis set superposition error (BSSE) correction and zero-point energy (ZPE). In this way, the lowest energy geometry can be approximated as the global optimal geometry. The interaction energy was calculated via Equation (5)

$$
\Delta E(\mathrm{AB})=E(\mathrm{AB})-E(\mathrm{~A})-E(\mathrm{~B})+\mathrm{BSSE}
$$

where $E(\mathrm{AB})$ is the energy of the $\mathrm{A}-\mathrm{B}$ complex and in the case of this work is IL-acetone, IL-chloroform, or the cation-anion complex. The lowest energy geometries are shown in Appendix A, and the interaction energy of those geometries is shown in Table 2. In addition, we can judge whether hydrogen bonds are formed by means of literature [18].

Table 2. The value $\Delta E(\mathrm{AB})$ of interaction energy between ionic liquid and solvent. All energies are given in $\mathrm{kJ} \cdot \mathrm{mol}^{-1}$.

\begin{tabular}{ccc}
\hline $\mathbf{A}$ & $\mathbf{B}$ & $\boldsymbol{\Delta} \boldsymbol{E}(\mathbf{A B})$ \\
\hline acetone & chloroform & -14.290 \\
[MMIM] $^{+}$ & {$[\mathrm{DMP}]^{-}$} & -387.833 \\
[EMIM] $^{+}$ & {$[\mathrm{DEP}]^{-}$} & -381.524 \\
acetone & {$[\mathrm{MMIM}][\mathrm{DMP}]$} & -24.519 \\
acetone & {$[\mathrm{EMIM}][\mathrm{DEP}]$} & -14.892 \\
chloroform & {$[\mathrm{MMIM}][\mathrm{DMP}]$} & -30.939 \\
chloroform & {$[\mathrm{EMIM}][\mathrm{DEP}]$} & -30.421 \\
\hline
\end{tabular}

By experiment, $\Delta E($ acetone + chloroform $)>\Delta E($ acetone $+[\mathrm{MMIM}][\mathrm{DMP}])>\Delta E($ chloroform + $[\mathrm{MMIM}][\mathrm{DMP}])>\Delta E\left([\mathrm{MMIM}]^{+}+[\mathrm{DMP}]^{-}\right)$. As the most probable structures, the $\Delta E$ (acetone + [MMIM][DMP]) is weaker than the $\Delta E$ (chloroform + [MMIM][DMP]). Therefore, it is easier for the ILs to attract chloroform molecules and to have a salting-out effect on acetone. Moreover, because the $\Delta E($ acetone $+[$ EMIM $][\mathrm{DEP}])>\Delta E($ acetone $+[\mathrm{MMIM}][\mathrm{DMP}])>\Delta E($ chloroform + $[\mathrm{EMIM}][\mathrm{DEP}]) \approx \Delta E($ chloroform $+[\mathrm{MMIM}][\mathrm{DMP}]),[\mathrm{EMIM}][\mathrm{DEP}]$ shows higher extraction efficiency than [MMIM][DMP].

\section{Conclusions}

The VLE data for the two systems of acetone + chloroform containing [MMIM][DMP] or [EMIM][DEP] were measured at $101.3 \mathrm{kPa}$. Two ILs have remarkable separation efficiency on the binary acetone-chloroform azeotropic system and can break the azeotrope when the mole fraction of ILs is over 0.15. Compared with [MMIM][DMP], [EMIM][DEP] produces a more significant effect on the VLE of acetone and chloroform. By use of the NRTL model, the experimental data correlated well. Besides, the results of the quantum chemical calculations indicate that chloroform had stronger affinity with ionic liquids than acetone, which is in accordance with the experiment results.

Author Contributions: Data Curation, Q.G.; Funding Acquisition, Z.Z.; Methodology, Z.Z.; Investigation, Q.G. and P.J.; Writing-Original Draft Preparation, Q.G.; Project Administration, Z.Z. and X.Z.; Supervision, Z.Z.

Funding: This research was funded by National Natural Science Foundation of China under grant number No. 51376036.

Acknowledgments: The authors want to thanks prof. Luo Yi's research group in Dalian University of Technology for helping us with the theoretical calculation in Gaussian 0.9 A.01.

Conflicts of Interest: The authors declare no conflict of interest. 


\section{Appendix A}

The structures were optimized by quantum chemical calculations.

When the bond length of $\mathrm{H} \cdots \mathrm{O}$ is less than $2.72 \AA$ and the bong angle of $\mathrm{C}-\mathrm{H} \cdots \mathrm{O}$, it is considered that the hydrogen bond is formed [18].

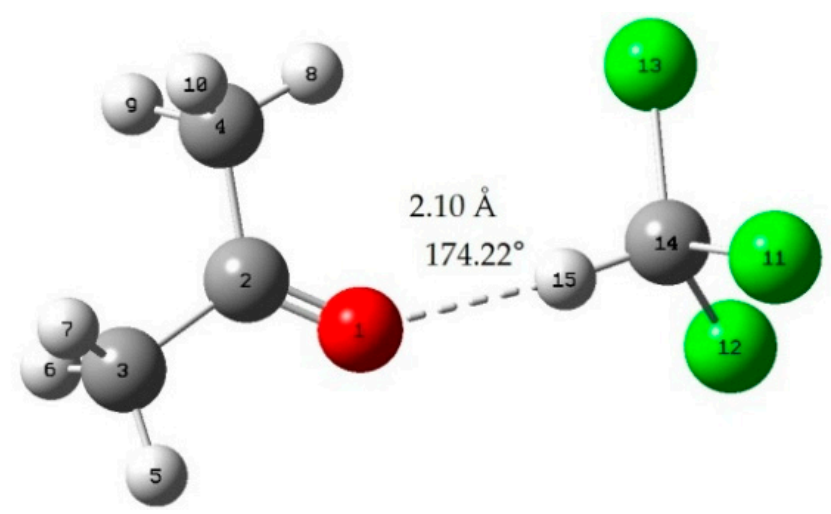

Figure A1. Acetone-chloroform; red: oxygen atom; green: chlorine atom gray: carbon atom; white: hydrogen atom; dotted line: hydrogen bond.

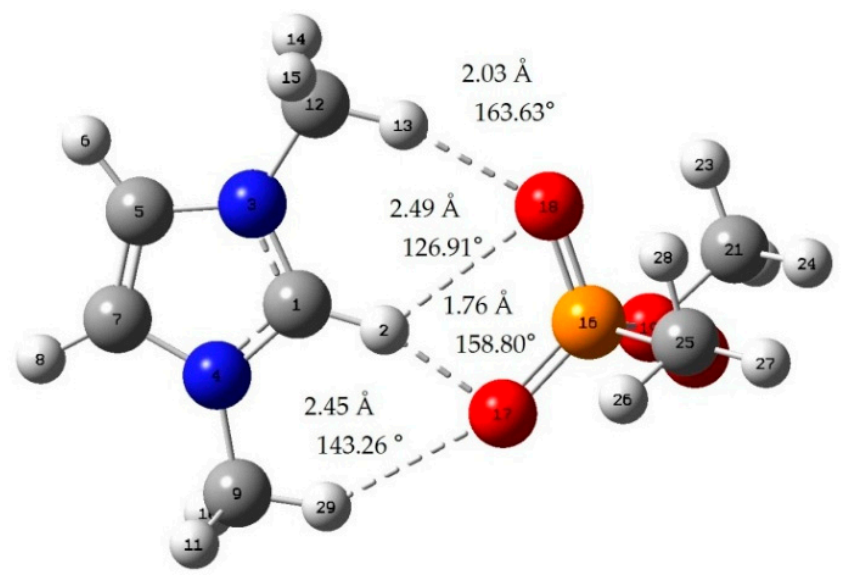

Figure A2. [MMIM][DMP]; red: oxygen atom; green: chlorine atom gray: carbon atom; white: hydrogen atom; blue: nitrogen atom; dotted line: hydrogen bond.

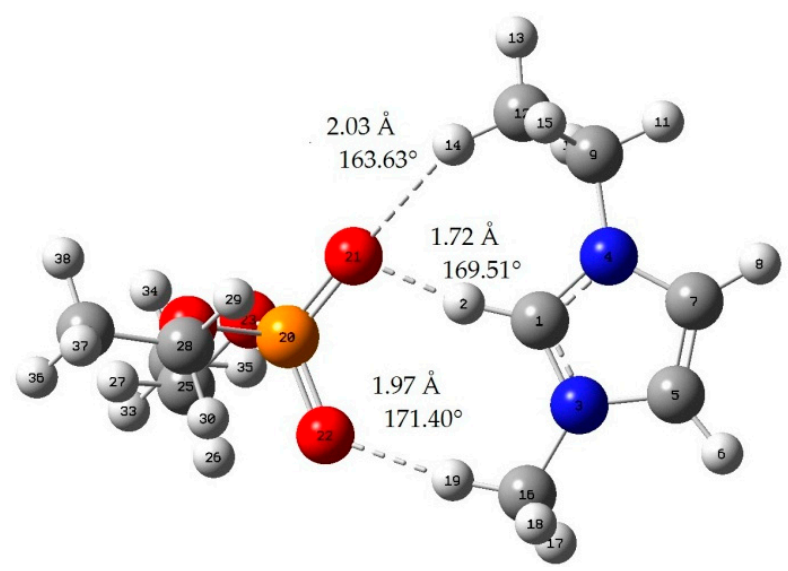

Figure A3. [EMIM][DEP]; red: oxygen atom; green: chlorine atom gray: carbon atom; white: hydrogen atom; blue: nitrogen atom; dotted line: hydrogen bond. 


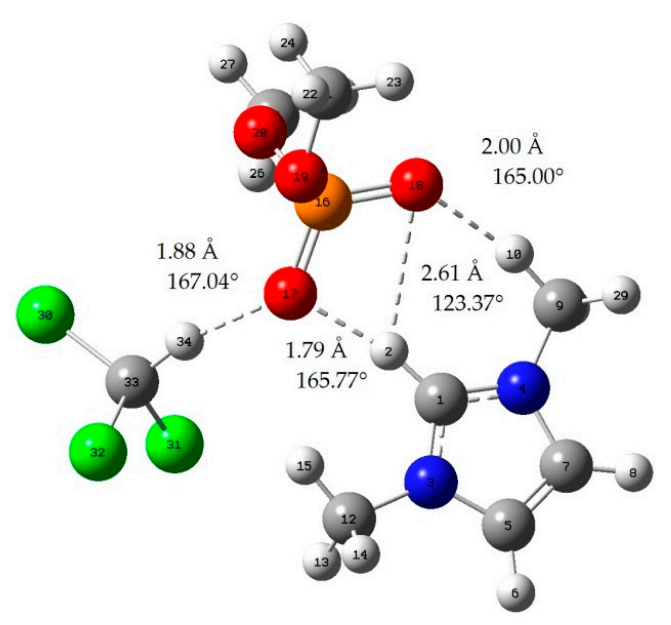

Figure A4. Chloroform-[MMIM][DMP]; red: oxygen atom; green: chlorine atom gray: carbon atom; white: hydrogen atom; blue: nitrogen atom; dotted line: hydrogen bond.

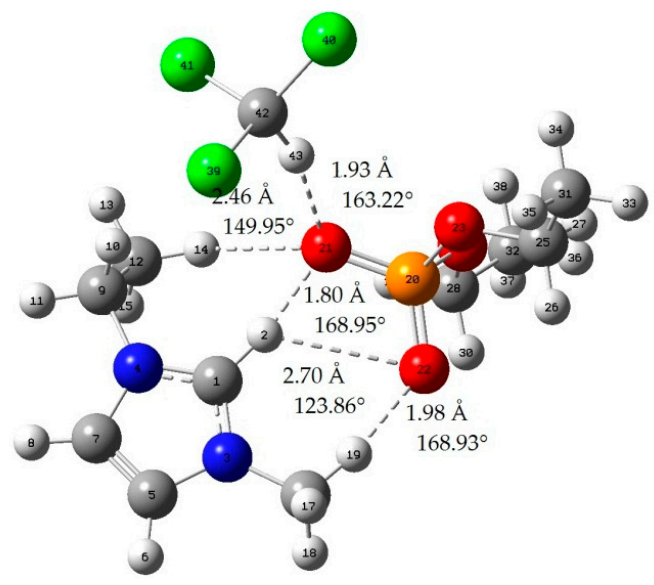

Figure A5. Chloroform-[EMIM][DEP]; red: oxygen atom; green: chlorine atom gray: carbon atom; white: hydrogen atom; blue: nitrogen atom; dotted line: hydrogen bond.

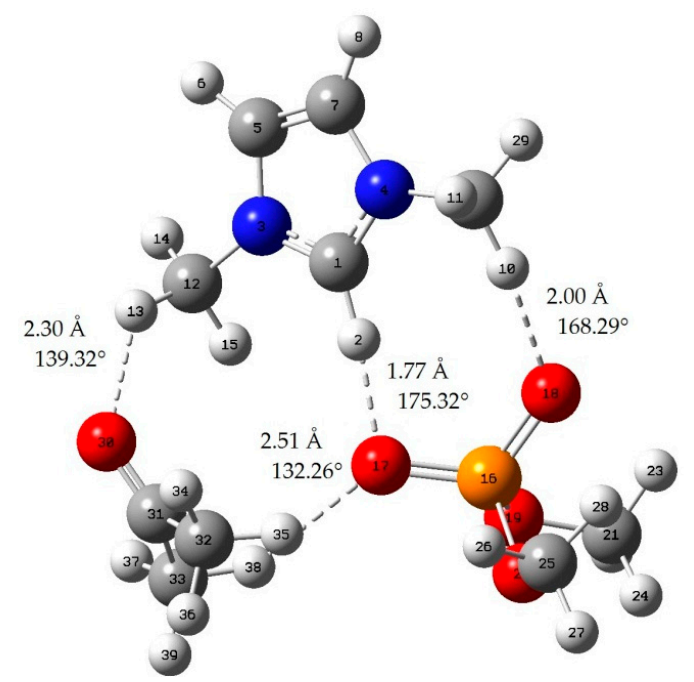

Figure A6. Acetone-[MMIM][DMP]; red: oxygen atom; green: chlorine atom gray: carbon atom; white: hydrogen atom; blue: nitrogen atom; dotted line: hydrogen bond. 


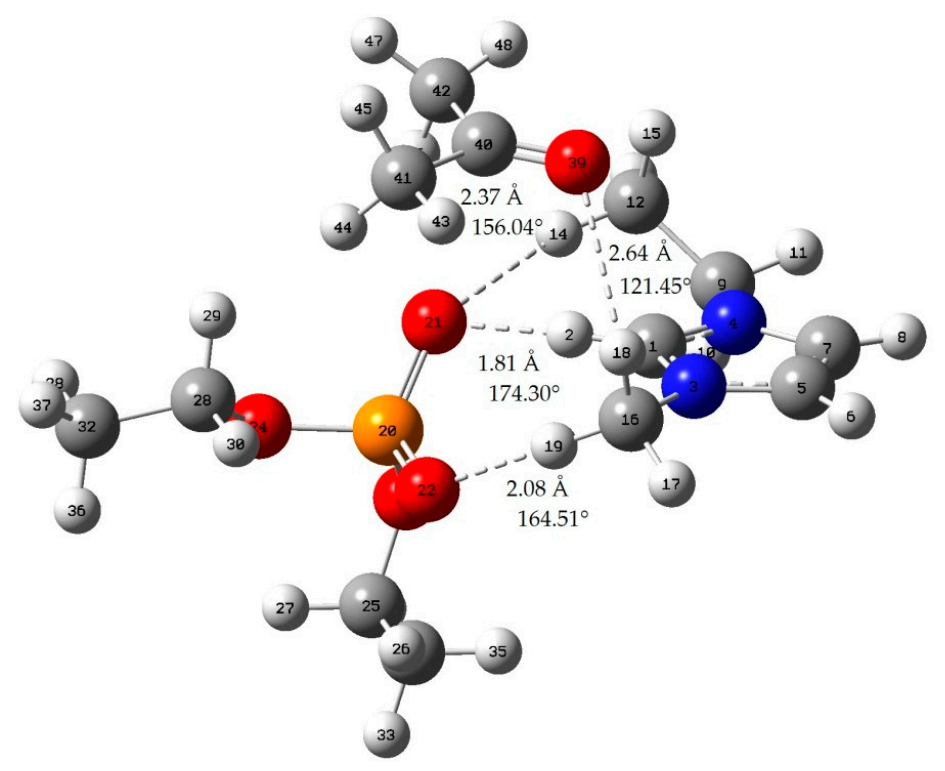

Figure A7. Acetone-[EMIM][DEP]; red: oxygen atom; green: chlorine atom gray: carbon atom; white: hydrogen atom; blue: nitrogen atom; dotted line: hydrogen bond.

\section{Appendix B}

Vapor-liquid equilibrium data of Figures 1-3.

Table A1. Vapor-liquid equilibrium data for the acetone (1) + chloroform (2) system at $101.3 \mathrm{kPa}$.

\begin{tabular}{ccc}
\hline T/K & $\mathbf{x}_{\mathbf{1}}$ & $\mathbf{y}_{\mathbf{1}}$ \\
\hline 335.7 & 0.102 & 0.067 \\
336.9 & 0.202 & 0.160 \\
337.6 & 0.301 & 0.280 \\
337.6 & 0.396 & 0.401 \\
336.9 & 0.494 & 0.544 \\
335.9 & 0.587 & 0.660 \\
334.5 & 0.679 & 0.765 \\
332.5 & 0.786 & 0.866 \\
331.0 & 0.893 & 0.945 \\
\hline
\end{tabular}

Standard uncertainties $\mathrm{u}\left(x_{1}\right)=\mathrm{u}\left(y_{1}\right)=0.002, \mathrm{u}(T)=0.1 \mathrm{~K}$.

Table A2. VLE data for the ternary system of acetone (1) + chloroform (2) + [MMIM][DMP] (3) at $101.3 \mathrm{kPa}$.

\begin{tabular}{cccccc}
\hline $\mathbf{x}_{\mathbf{3}}$ & $\mathbf{T} / \mathbf{K}$ & $\mathbf{x}_{\mathbf{1}}{ }^{\prime}$ & $\mathbf{y}_{\mathbf{1}}{ }^{\mathbf{e x p}}$ & $\mathbf{y}_{\mathbf{1}}{ }^{\text {cal }}$ & $\boldsymbol{\alpha}_{\mathbf{1 2}}$ \\
\hline 0.103 & 337.39 & 0.104 & 0.098 & 0.102 & 0.971 \\
0.100 & 338.67 & 0.202 & 0.211 & 0.226 & 1.060 \\
0.100 & 339.31 & 0.290 & 0.339 & 0.354 & 1.257 \\
0.100 & 338.93 & 0.396 & 0.485 & 0.509 & 1.435 \\
0.100 & 338.23 & 0.476 & 0.610 & 0.617 & 1.723 \\
0.100 & 336.51 & 0.583 & 0.732 & 0.742 & 1.956 \\
0.100 & 334.7 & 0.678 & 0.831 & 0.832 & 2.334 \\
0.100 & 332.58 & 0.785 & 0.910 & 0.908 & 2.776 \\
0.100 & 330.97 & 0.887 & 0.960 & 0.960 & 3.068 \\
0.150 & 338.8 & 0.100 & 0.109 & 0.116 & 1.111 \\
0.152 & 340.21 & 0.194 & 0.242 & 0.252 & 1.326 \\
\hline
\end{tabular}


Table A2. Cont.

\begin{tabular}{cccccc}
\hline $\mathbf{x}_{\mathbf{3}}$ & $\mathbf{T} / \mathbf{K}$ & $\mathbf{x}_{\mathbf{1}}{ }^{\prime}$ & $\mathbf{y}_{\mathbf{1}}{ }^{\exp }$ & $\mathbf{y}_{\mathbf{1}}{ }^{\text {cal }}$ & $\boldsymbol{\alpha}_{\mathbf{1 2}}$ \\
\hline 0.151 & 340.45 & 0.282 & 0.382 & 0.387 & 1.571 \\
0.150 & 339.84 & 0.372 & 0.513 & 0.521 & 1.780 \\
0.150 & 338.34 & 0.486 & 0.665 & 0.672 & 2.104 \\
0.151 & 336.65 & 0.578 & 0.773 & 0.773 & 2.476 \\
0.150 & 334.78 & 0.672 & 0.852 & 0.852 & 2.810 \\
0.150 & 332.75 & 0.782 & 0.921 & 0.921 & 3.254 \\
0.150 & 330.94 & 0.884 & 0.968 & 0.966 & 3.994 \\
0.199 & 342.07 & 0.107 & 0.153 & 0.149 & 1.506 \\
0.200 & 343.07 & 0.187 & 0.279 & 0.279 & 1.679 \\
0.199 & 343.16 & 0.266 & 0.418 & 0.407 & 1.983 \\
0.200 & 341.34 & 0.369 & 0.575 & 0.564 & 2.317 \\
0.201 & 339.6 & 0.468 & 0.697 & 0.692 & 2.619 \\
0.200 & 337.61 & 0.553 & 0.791 & 0.780 & 3.065 \\
0.201 & 335.23 & 0.671 & 0.874 & 0.873 & 3.400 \\
0.201 & 333.06 & 0.784 & 0.930 & 0.934 & 3.689 \\
0.202 & 331.04 & 0.883 & 0.970 & 0.971 & 4.341 \\
\hline
\end{tabular}

Standard uncertainties $\mathrm{u}\left(x_{1}\right)=\mathrm{u}\left(y_{1}\right)=0.002, \mathrm{u}(T)=0.1 \mathrm{~K}, \mathrm{ARD}=1.8193 \%$.

Table A3. VLE data for the ternary system of acetone (1) + chloroform (2) + [EMIM][DEP] (3) at $101.3 \mathrm{kPa}$.

\begin{tabular}{cccccc}
\hline $\mathbf{x}_{\mathbf{3}}$ & $\mathbf{T} / \mathbf{K}$ & $\mathbf{x}_{\mathbf{1}}{ }^{\prime}$ & $\mathbf{y}_{\mathbf{1}}{ }^{\mathbf{e x p}}$ & $\mathbf{y}_{\mathbf{1}}{ }^{\mathbf{c a l}}$ & $\boldsymbol{\alpha}_{\mathbf{1 2}}$ \\
\hline 0.100 & 338.18 & 0.100 & 0.099 & 0.105 & 0.989 \\
0.100 & 339.39 & 0.195 & 0.215 & 0.230 & 1.128 \\
0.100 & 339.83 & 0.287 & 0.348 & 0.365 & 1.325 \\
0.100 & 339.68 & 0.376 & 0.484 & 0.495 & 1.563 \\
0.100 & 338.74 & 0.477 & 0.614 & 0.634 & 1.746 \\
0.100 & 337.33 & 0.573 & 0.742 & 0.746 & 2.143 \\
0.100 & 335.10 & 0.679 & 0.834 & 0.843 & 2.382 \\
0.101 & 333.18 & 0.788 & 0.919 & 0.917 & 3.031 \\
0.100 & 331.37 & 0.897 & 0.970 & 0.968 & 3.665 \\
0.150 & 340.81 & 0.097 & 0.115 & 0.124 & 1.216 \\
0.150 & 341.67 & 0.192 & 0.256 & 0.267 & 1.443 \\
0.150 & 342.21 & 0.269 & 0.392 & 0.389 & 1.756 \\
0.150 & 341.41 & 0.365 & 0.535 & 0.536 & 1.998 \\
0.150 & 340.03 & 0.456 & 0.664 & 0.658 & 2.354 \\
0.149 & 337.91 & 0.567 & 0.788 & 0.779 & 2.837 \\
0.150 & 336.30 & 0.663 & 0.863 & 0.859 & 3.198 \\
0.150 & 333.88 & 0.781 & 0.933 & 0.929 & 3.920 \\
0.150 & 332.20 & 0.877 & 0.971 & 0.968 & 4.726 \\
0.199 & 344.21 & 0.093 & 0.143 & 0.144 & 1.626 \\
0.199 & 344.81 & 0.178 & 0.293 & 0.290 & 1.913 \\
0.200 & 345.48 & 0.251 & 0.423 & 0.414 & 2.186 \\
0.200 & 344.37 & 0.345 & 0.563 & 0.562 & 2.443 \\
0.200 & 342.76 & 0.430 & 0.690 & 0.675 & 2.946 \\
0.205 & 339.93 & 0.556 & 0.812 & 0.809 & 3.446 \\
0.200 & 337.70 & 0.664 & 0.882 & 0.884 & 3.783 \\
0.199 & 335.58 & 0.766 & 0.937 & 0.936 & 4.525 \\
0.198 & 332.63 & 0.908 & 0.981 & 0.982 & 5.201 \\
\hline Sandard uncertainties $\mathrm{u}\left(x_{1}\right)=\mathrm{u}\left(y_{1}\right)=0.002, \mathrm{u}(T)=0.1 \mathrm{~K}, \mathrm{ARD}=1.7948 \%$.
\end{tabular}




\section{References}

1. Luyben, W.L. Comparison of extractive distillation and pressure-swing distillation for acetone/chloroform separation. Comput. Chem. Eng. 2013, 50,1-7. [CrossRef]

2. Dai, C.; Lei, Z.; Xi, X.; Zhu, J.; Chen, B. Extractive distillation with a mixture of organic solvent and ionic liquid as entrainer. Ind. Eng. Chem. Res. 2014, 53, 15786-15791. [CrossRef]

3. Lei, Z.; Dai, C.; Zhu, J.; Chen, B. Extractive distillation with ionic liquids: A review. AIChE J. 2014, 60, 3312-3329. [CrossRef]

4. Luyben, W.L. Control of the maximum-boiling acetone/chloroform azeotropic distillation system. Ind. Eng. Chem. Res. 2008, 47, 6140-6149. [CrossRef]

5. Lei, Z.; Chen, B.; Ding, Z. Special Distillation Processes; Elsevier: New York, NY, USA, 2005.

6. Rezabal, E.; Schäfer, T. First principle approach to solvation by methylimidazolium-based ionic liquids. J. Phys. Chem. B 2013, 117, 553-562. [CrossRef] [PubMed]

7. Lyu, Z.; Zhou, T.; Chen, L.; Ye, Y.; Kai, S.; Qi, Z. Simulation based ionic liquid screening for benzene-cyclohexane extractive separation. Chem. Eng. Sci. 2014, 115, 186-194. [CrossRef]

8. Dong, K.; Song, Y.; Liu, X.; Cheng, W.; Yao, X.; Zhang, S. Understanding structures and hydrogen bonds of ionic liquids at the electronic level. J. Phys. Chem. B 2012, 116, 1007-1017. [CrossRef] [PubMed]

9. Li, Q.; Liu, P.; Cao, L.; Wen, F.; Zhang, S.; Wang, B. Vapor-liquid equilibrium for tetrahydrofuran + methanol + tetrafluoroborate-based ionic liquids at $101.3 \mathrm{kPa}$. Fluid Phase Equilibr. 2013, 360, 439-444. [CrossRef]

10. Hiaki, T.; Kawai, A. Vapor-liquid equilibria determination for a hydrofluoroether with several alcohols. Fluid Phase Equilibr. 1999, 158, 979-989. [CrossRef]

11. Kojima, K.; Tochigi, K.; Kurihara, K.; Nakamichi, M. Isobaric vapor-liquid equilibria for acetone + chloroform + benzene and the three constituent binary systems. J. Chem. Eng. Data 1991, 36, 343-345. [CrossRef]

12. Yaws, C.L.; Yang, H.C. To estimate vapor pressure easily. Hydrocarbon Process. 1989, 68, 10.

13. Renon, H.; Prausnitz, J.M. Local compositions in thermodynamic excess functions for liquid mixtures. AIChE J. 1968, 14, 135-144. [CrossRef]

14. Li, Q.; Cao, L.; Sun, X.; Liu, P.; Wang, B. Isobaric vapor-liquid equilibrium for ethyl acetate + acetonitrile + 1-butyl-3-methylimidazolium hexafluorophosphate at $101.3 \mathrm{kPa}$. J. Chem. Eng. Data 2013, 58, 1112-1116. [CrossRef]

15. Simoni, L.D.; Ficke, L.E.; Lambert, C.A.; Stadtherr, M.A.; Brennecke, J.F. Measurement and prediction of vapor-liquid equilibrium of aqueous 1-ethyl-3-methylimidazolium-based ionic liquid systems. Ind. Eng. Chem. Res. 2010, 49, 3893-3901. [CrossRef]

16. Li, Q.; Zhang, S.; Ding, B.; Cao, L.; Liu, P.; Jiang, Z.; Wang, B. Isobaric vapor-liquid equilibrium for methanol + dimethyl carbonate + trifluoromethanesulfonate-based ionic liquids at $101.3 \mathrm{kpa}$. J. Chem. Eng. Data 2014, 59, 3488-3494. [CrossRef]

17. Frisch, M.; Trucks, G.; Schlegel, H.; Scuseria, G.; Robb, M.; Cheeseman, J.; Scalmani, G.; Barone, V.; Mennucci, B.; Petersson, G. Gaussian 09, Rev. A. 01; Gaussian Inc.: Wallingford, CT, USA, 2009.

18. Steiner, T. The hydrogen bond in the solid state. Angew. Chem. Int. Ed. 2010, 41, 48-76. [CrossRef]

(C) 2018 by the authors. Licensee MDPI, Basel, Switzerland. This article is an open access article distributed under the terms and conditions of the Creative Commons Attribution (CC BY) license (http:// creativecommons.org/licenses/by/4.0/). 